\title{
Las Exposiciones de Museos: Un Espacio en Disputa por los Sentidos y Significados del Medio Ambiente y sus Problemas Socioambientales
}

\author{
As Exposições de Museus: Um Espaço em Disputa pelos \\ Sentidos e Significados do Meio Ambiente e seus Problemas \\ Socioambientais
}

\section{Museum Exhibitions: A Space in Dispute for the Senses and Meanings of the Environment and its Socio-Environmental Problems}

\author{
Iván Borroto Rodríguez \\ Yanina Micaela Sammarco \\ Cuba \\ Brasil
}

El presente artículo se propone contribuir a las discusiones sobre el papel de museos frente a la crisis ambiental, mediante la discusión de la presentación del medio ambiente y de sus problemas socioambientales en las exposiciones. En esa dirección, se presenta inicialmente una revisión histórica sobre la constitución de los museos, a partir de algunas transformaciones experimentadas por sus colecciones. A continuación se desarrolla una discusión sobre la educación de los visitantes en el ámbito de las dimensiones tiempo, espacio y objeto. A partir de esa discusión se analizan las posibilidades comunicativas y educativas de las exposiciones. Por último, se presentan reflexiones sobre la exhibición del medio ambiente y sus problemas en las exposiciones de museos. A partir de este estudio, se percibe al museo público con posibilidades para la educación de la ciudadanía en cuestiones sociambientales. Por otro lado, se aprecia que en la práctica el tratamiento dado al medio ambiente y a sus problemas socioambientales no atiende a su naturaleza multifacética. Esta situación lleva a ubicar a museos públicos en una posición desfavorable frente a la posibilidad de contribuir al enfrentamiento de la crisis ambiental.

Palabras claves: Museo; exposiciones; medio ambiente; problemas socioambientales.

Este artigo tem como objetivo contribuir para as discussões sobre o papel dos museus no enfrentamento da crise ambiental, através da discussão da apresentação do meio ambiente e seus problemas socioambientais nas exposições. Em tal sentido, apresenta- 
se inicialmente uma revisão histórica sobre a constituição dos museus, com base em algumas transformações experimentadas por suas coleções. Na sequência discute-se sobre a educação dos visitantes no âmbito das dimensões tempo, espaço e objeto. A partir dessa discussão são analisadas as possibilidades comunicativas e educativas das exposições. Por último, são apresentadas reflexões sobre a problemática da apresentação do meio ambiente e seus problemas nas exposições do museu. A partir deste estudo, percebe-se o museu público como um possível espaço de favorecimento da educação para a cidadania no que tange a questões socioambientais. Por outro lado, destaca-se que, na prática, o tratamento dado ao meio ambiente e aos seus problemas socioambientais não atende a sua natureza multifacetada. Essa situação leva a colocar os museus públicos em uma posição desfavorável diante da possibilidade de contribuir para o enfrentamento da crise ambiental.

Palavras-chave: Museu; exposições; meio ambiente; problemas socioambientais.

The present manuscript aims to contribute to the debate on the role of traditional museums in light of the current environmental crisis. For this purpose, we discuss the environmental exhibitions and social-environmental problems exposed on traditional museums. In this sense, we start from a historical review on the constitution of museums, based on some transformations experienced by their collections. Next, we discuss the education of visitors in terms of time, space and object. Based on this discussion, we analyze the communicative and educational possibilities of the exhibitions. Finally, we address the problematic of presenting the environment and its problems in museum exhibitions. From this study, we suggest that museums are a major possibility for citizenship teaching in terms of environmental issues. On the other hand, in practice, the way of treating the environment and social-environmental problems falls short considering the complex and multifaceted nature of the subject. For this reason, we agree that traditional museums stand in an unfavorable position in supporting the fight against the environmental crisis.

Keywords: Museum; exhibitions; environment; socio-environmental problems.

\section{Introducción}

El museo puede pensarse como una idea polisémica que ha atravesado los siglos a cuestas del interés del ser humano por la retención de su mundo material en el tiempo. Mundo material que como acervo del museo, pasa a representar un universo cultural que se debate entre el dogma y la creatividad, entre la exclusión y la inclusión, y entre la memoria y el olvido.

En ese viaje a través del tiempo y afectada por los diferentes contextos, la idea de museo ha devenido en una amplia tipología en ánimo de seguir diversificándose, pues de acuerdo con Macdonald y Silverstone (1990), con el abandono de la presentación de las viejas taxonomías por la adopción de discursos expositivos basados en ideas e 
historias, la exposición va desligándose de las colecciones, dando origen a un espacio semántico que puede ser colonizado por nuevas variantes de museos.

Entre esas posibles variantes, el presente artículo se refiere a aquellos museos públicos que de alguna forma socializan en sus exposiciones cuestiones relativas al medio ambiente y a sus problemas socioambientales. Esta acotación, lleva a tener en cuenta, principalmente, pero no solo, a un grupo de museos públicos denominados como museos científicos o de ciencias, entre los cuales usualmente son incluidos museos de historia natural, museos de ciencia e industria, y museos y centros de ciencias.

Los orígenes del museo público pueden identificarse en la gradual apertura de las colecciones privadas de los gabinetes de curiosidades de la Europa de los siglos XVII, XVIII y XIX. El auge de esta institución, principalmente durante los siglos XVIII y XIX, estuvo relacionado, según Hooper-Greenhill (2007), a la instauración de los nuevos estados republicanos. En ese contexto, apunta la autora, el museo público se constituyó en un nuevo espacio cultural que funcionaba como instrumento de los gobiernos, para exponer la decadencia de las derrotadas monarquías y la utilidad del nuevo régimen. En el siglo XIX, influido por los ideales científicos y educativos de las instituciones museísticas europeas, el museo público comienza a establecerse en las capitales de algunos estados americanos, para adentrarse más tarde en sus territorios.

Con la apertura de las colecciones privadas a un público no especializado en su estudio, el acervo del museo, según Van-Praët (1996), experimenta una tensión entre los intereses de coleccionadores y estudiosos, que ven en esta nueva situación un riesgo para la preservación de las piezas, y los intereses por socializar ese acervo que respondían a la necesidad de difundir conocimientos científicos y de evitar el aislamiento de la comunidad científica. Esa tensión, según el autor, va a solucionarse con la disposición de espacios privados para el almacenamiento, preservación y estudio del acervo, y de espacios públicos para la exposición de parte de ese acervo.

Ese movimiento experimentado por el museo público lleva al surgimiento de las exposiciones temáticas, donde el objeto es expuesto como testimonio de las ideas y teorías científicas surgidas en la época, y ya no tanto, en el marco de lógicas científicas de clasificación. Ese cambio en las exposiciones, siguiendo a Hooper-Greenhill (2003), también es el resultado de un nuevo estado del conocimiento alcanzado por las ciencias, que de describir el mundo en el marco de lógicas científicas de clasificación, pasa a interesarse por el origen, funcionamiento e interrelaciones, del mundo vivo y los elementos de su entorno.

En el museo público del siglo XIX, pueden situarse los antecedentes educativos de los museos de la actualidad. No obstante, es importante señalar, que para el siglo de la luces, según Hein (2006), la labor educativa del museos era esporádica y a menudo insatisfactoria, debido a la existencia de escasos precedentes históricos y teorías para orientar la educación. Por otra parte, Bennet, (1995) citado en Hooper-Greengill (2010), opina que la dimensión moral, a veces proselitista, es una de las características principales de la educación en estos espacios. 
Según Hein (2005), el rol educativo del museo público fue menguando hacia finales del siglo XIX, pues ya para esa época la escuela había consolidado su papel frente a la sociedad como principal institución para la educación de los ciudadanos. Posterior a la Segunda Guerra Mundial, de acuerdo con Hein (2006), el rol educativo del museo público vuelve a renacer, con el reconocimiento de la educación como una función legitima de la institución. Muestra fehaciente de esta opinión puede encontrarse en la celebración de reuniones internacionales ${ }^{1}$, auspiciadas por el International Council of Museums (ICOM), durante las décadas del 50 y del 60, del siglo XX.

El museo público del siglo XIX, siguiendo a Hooper-Greenhill (2000), es una institución que se caracteriza, más allá de su diversidad, por una dicotomía en la organización de sus espacios, que se expresa en la existencia de espacios privados para la producción del conocimiento y de espacios públicos para su consumo. En los espacios privados el conocimiento es producido en los límites de disciplinas científicas, que determinan la organización del acervo. En los espacios públicos el conocimiento es transmitido a un público que se considera desconocedor de los temas presentados en las exposiciones.

Este modelo de museo se sitúa en el origen de los museos públicos de la actualidad, y ha sido durante gran parte del siglo XX, una presencia hegemónica en buena parte del universo museístico. No obstante, sin negar su presencia en instituciones museísticas contemporáneas, es importante señalar la presencia de otras fuerzas traducidas en ideas y modelos que pujan por la superación del ideal de museo público del siglo XIX. En este sentido, tal vez, lo más apropiado seria, siguiendo a Lindauer (2007), considerar al museo público de la actualidad, como una institución no monolítica donde conviven cualidades del ideal de museo público del siglo XIX, con cualidades emergentes de otros modelos de museos posibles.

Esa convivencia, aparentemente pacifica, de cualidades pertenecientes a diferentes modelos de museos, se percibe como la expresión de fuerzas en tensión, representantes de intereses diversos y frecuentemente antagónicos, que pujan por la hegemonía discursiva del museo, posicionándolo como una institución conservadora o transformadora de los valores culturales y del orden establecido.

Desde la segunda mitad del siglo XX, con las demandas de la sociedad sobre estas instituciones y el desarrollo de nuevas museologías, el museo ha ido permeabilizando sus muros a la entrada de teorías y modelos provenientes de otras áreas de conocimiento como la educación, la sociología, y la comunicación, en dirección a la democratización de sus funciones. No obstante, ese impulso democratizador del museo debe mirarse con cautela, pues de acuerdo con Chagas (2011), " $[\ldots]$ cualquier intento de reducir los museos a un único aspecto, corre el riesgo de no dar cuenta de la complejidad del mundo museístico en el mundo contemporáneo" (p. 14, traducción nuestra). Una complejidad, que desde una perspectiva crítica lleva a entender a los museos como " $[. .$.$] lugares de$

1 Seminário de Brooklin (1952), Atenas (1954), Rio de Janeiro (1958), Tóquio (1960), México (1962), Lagos (1964), entre otros. 
memoria y de olvido, así como lugares de poder, de combate, de conflicto, de litigio, de silencio y de resistencia; en ciertos casos, pueden hasta ser no lugares" (Chagas, 2011, p. 14, traducción nuestra).

Como parte de ese movimiento de democratización, el museo público también ha prestado oídos a los problemas que afectan a las sociedades contemporáneas, y ha pasado a representarlos en sus exposiciones. Con la crisis ambiental, un grupo de esos problemas representados en las exposiciones de museos, atienden a problemas socioambientales actuales, sumándose a formas tradicionales de representar el medio ambiente en las exposiciones.

A la luz de las consideraciones anteriores, es posible afirmar que la presentación del medio ambiente y sus problemas ambientales en las exposiciones entra en la lógica discursiva del museo, en el marco de la cual puede estarse promoviendo, a partir de diversos interese en juego, discursos afines o no con la necesidad de subversión de la crisis ambiental.

Ese aspecto motiva la realización de este artículo, que se propone discutir el papel de museos públicos en la formación de una ciudadanía en materia socioambiental, como contribución al enfrentamiento de un problema contemporáneo como puede ser la crisis ambiental. En ese sentido, se reflexiona sobre la presentación del medio ambiente y sus problemas socioambientales en las exposiciones, teniendo en cuenta las particularidades, limitaciones y posibilidades de la comunicación y la educación en el espacio expositivo del museo, pues de estas depende la eficacia del mensaje.

Este estudio, se inserta en el marco de los esfuerzos dirigidos a ampliar la dimensión socioambiental de los museos, pues de acuerdo con Mountinho (2014) "La abertura del museo al medio y a su relación orgánica con el contexto social que le da vida ha provocado la necesidad de elaborar y esclarecer relaciones, nociones y conceptos, que pueden dar cuenta de este proceso" (p. 423, traducción de nuestra).

\section{La educación en el museo: el tiempo, el espacio, y el objeto}

La educación en el museo se entiende en el marco de la educación no formal ${ }^{2}$, como parte del concepto de educación permanente, lo que denota la importancia del museo como una institución educativa, que junto a otras, incide en la educación de los ciudadanos a lo largo de toda su vida.

De acuerdo con La Belle (1976), la educación no formal es una modalidad educativa que al igual que la modalidad educativa formal e informal, debe ser vista no como una entidad de límites definidos, sino más bien como un modo predominante o de énfasis. Desde este punto de vista, en un mismo proceso educativo existe una modalidad predominante y otras secundarias, que en conjunto pueden contribuir para el logro de los objetivos educativos. Esta idea llevada al interior del museo, permite un posicionamiento más flexible frente a la educación que se realiza en esos espacios, lo que para nada apunta a considerar al museo como una escuela o como un centro de

2 En la literatura al español y al portugués. 
información.

En el espíritu de considerar a la educación no formal como una categoría sin límites precisos, que debe predominar en las acciones educativas de los museos, es posible definir algunas características de la educación en estas instituciones. En tal sentido, el museo puede ser utilizado por todos los ciudadanos, que por interés propio acuden a las instalaciones del museo, donde se involucran en acciones educativas con un cierto grado de estructuración y sistematización, desarrolladas al margen del sistema educativo reglado (Borroto, 2019). En el marco de estas características, la educación en el museo, siguiendo a Silverstone (2002), Cury (2005a), y Marandino et al. (2008), puede ser singularizada a partir de dimensiones como: el tiempo, el espacio y el objeto.

El tiempo consumido y la trayectoria recorrida en el espacio expositivo transcurren en parte bajo la elección y el control de los visitantes durante una visita libre. Esto se traduce en que más allá de los recursos museográficos utilizados para guiar la trayectoria y prolongar la permanencia en la exposición, los visitantes crean su propio itinerario y autorregularán su tiempo de permanencia en las exposiciones, en base a motivaciones construidas a partir de experiencias previas a la visita al museo. Un poco diferente en una visita mediada, este control parcial del visitante sobre su experiencia en el espacio expositivo varía en dependencia del rol más o menos protagónico del mediador durante la visita.

Esa posibilidad del visitante de realizar elecciones propias y de autorregular el tiempo durante una visita libre se constituye en la base de un tipo de aprendizaje de trasfondo constructivista, reportado para museos y denominado como de Free-Choice learning (Falk, 2005; Falk \& Dierking, 2000; Falk et al., 2006; Falk et al., 2009).

Free-Choice learning o aprendizaje por cuenta propia, como se le conoce en español, es un aprendizaje que excede al espacio expositivo, pues se produce estrechamente relacionado a motivaciones y experiencias previas a la visita al museo, y se complementa con experiencias de aprendizaje futuras. Acontece como una construcción individual, influida y contextualizada al ambiente físico, la sociedad, y la cultura (Falk, 2005; Falk, \& Dierking, 2000; Falk et al., 2006).

La entrada de esta concepción de aprendizaje al espacio expositivo del museo, inevitablemente arremete contra la forma tradicional en la que son presentadas las informaciones. En esa forma de presentación tradicional, la exposición se asemeja a un libro de texto, en el que las informaciones son dispuestas de forma jerárquica y secuencial para contar historias, que se suponen sean aprehendidas de la misma manera por el visitante.

Un museo consciente de la concepción de aprendizaje por cuenta propia, se acercaría a construir exposiciones caracterizadas por Hein (2002) como de constructivistas. Esas exposiciones, según el autor, no presentarían una ruta específica, así como tampoco un principio o un fin. Presentarían toda una gama de puntos de vista sobre un tema, y ofrecerían la oportunidad al visitante de conectar con objetos y experiencias que remitan a sus experiencias de vida. 
Si bien la experiencia del visitante en el espacio expositivo, principalmente en una visita libre, transcurre en parte bajo la posibilidad de realizar elecciones propias, las características del espacio pueden influir sobre estas elecciones y sobre la propia experiencia de aprendizaje de los visitantes. En este sentido, Maxwell y Evans (2002) explican que esta influencia ocurre a partir de atributos físicos como la temperatura, la iluminación, el tamaño de los espacios, entre otros aspectos.

El potencial educativo de la exposición se hace efectivo a partir de la incorporación del mensaje al cotidiano de las personas (Cury, 2013). Desde este argumento, puede pensarse a la exposición como una importante herramienta educativa del museo, que por sí sola, puede propiciar aprendizajes en sus visitantes. Para que este aprendizaje se produzca, siguiendo a Hooper-Greenhill (2004), los visitantes deben sentirse en ambientes seguros y confortables, para estar en condiciones de buscar nuevas informaciones, disfrutar de sensaciones estéticas y ampliar el rango de conocimiento.

La educación en el museo se desarrolla y debe acontecer basada en la interacción de los visitantes con los objetos expuestos en las exposiciones, teniendo en cuenta al "[...] objeto material como vector de conocimiento, comunicación y de construcción de significados culturales" (Cury, 2005 b, p. 364, traducción nuestra). Es esta educación por el objeto la que le aporta una marca distintiva al museo, en el ámbito de las instituciones culturales que participan de la educación permanente, o a lo largo de toda la vida de los ciudadanos.

El objeto es portador de una biografía particular que se construye en base a los significados que va adquiriendo en el contexto de los diferentes ambientes políticos, culturales, económicos y sociales por los que circula. Es por estas biografías particulares surgidas en el tráfico de las relaciones humanas, que los objetos son seleccionados por los museos para en nombre de su sociedad, ser atesorados, estudiados y exhibidos (Silverstone, 2002).

El visitante en su interacción con los objetos, ya sea solamente por la observación o involucrando otros órganos de los sentidos, siguiendo a Hooper-Greenhill (1988), es capaz de construir abstracciones o de desarrollar conceptos a partir de experimentar la materialidad del objeto. La interacción con el objeto en función de la comprensión y el aprendizaje, según esta autora, es más eficaz que cuando se parte de abstracciones puras, pues la cognición, la comprensión, la integración como un proceso mental, y la recordación, son más eficaces cuando se trata de los aspectos materiales.

Una vez en las exposiciones, los objetos son exhibidos en asociación con elementos contextualizadores, en el marco de lógicas de clasificación y agrupación, en función del conocimiento aceptado como verdadero por la institución. En estas presentaciones, se representan fenómenos, historias o realidades, que favorecen y direccionan la comunicación de unos significados en lugar de otros.

En aquellos museos que objetivan la socialización de un discurso expositivo de marcado matiz científico, los elementos contextualizadores suelen ser textos de apoyo, maquetas, fotografías e imágenes. Esos elementos junto a los objetos expuestos, de 
acuerdo con (Marandino, 2002), aportan toda una gama de signos y señales sobre las cuales se construye el discurso expositivo.

La presentación del objeto por sí solo, en este tipo de museos, sin un entorno que lo contextualice, puede obstaculizar y hasta impedir su comprensión, así como frustrar la intencionalidad comunicativa de lo que se expone. De acuerdo con Morin (2003), el conocimiento válido es aquel que es capaz de situar una información en su contexto. Para que sea posible la producción de sentidos durante la comprensión, siguiendo a Morin (2003), “[...] es una necesidad cognitiva insertar un conocimiento particular en su contexto y situarlo en su conjunto" (p. 16, traducción nuestra).

Espacio, tiempo, y objeto forman una trilogía que circunscritas a las posibilidades de la educación no formal, singularizan el proceso educativo en el espacio expositivo. Museos conscientes de esta singularidad pueden desempeñar un papel educativo destacado en la formación de los ciudadanos a lo largo de toda su vida. Esa singularidad educativa del museo, adquiere un significado especial si se considera al museo en el ámbito de instituciones culturales, que compiten por la concesión de fondos ya de por sí limitados por las crisis económicas y las políticas liberales. Ante esta realidad el museo necesita, si quiere sobrevivir, ofrecer un servicio educativo singular en función de sus potencialidades educativas.

\section{Perspectivas de la educación en el museo}

La educación y la comunicación en el espacio expositivo se entienden de forma integrada. De acuerdo con Cury (2005 a), “[...] en toda acción pública desarrollada por el museo hay un carácter educativo, toda exposición educa y toda acción educativa se efectúa porque la comunicación se ha efectuado" (p. 17, traducción nuestra).

Muchas exposiciones siguiendo a Hooper-Greenhill (2007), se comportan como un producto comunicativo que expresa características en común con la comunicación de masas, que se caracteriza por ser una forma de comunicación unidireccional, de gran alcance en cuanto número de receptores, en la que el emisor representado en el papel del curador permanece ausente físicamente.

Es válido aclarar que ese enfoque de la comunicación, conocido como modelo de transmisión de la información, no niega la existencia de diferentes mecanismos de retroalimentación como parte del proceso de implementación de las exposiciones. No obstante, estos mecanismos no son capaces de superar la polaridad de la comunicación, en la cual el curador crea el mensaje a ser transmitido a los visitantes, considerados como cajas o recipientes vacíos a llenar (Cury b, 2005).

La unidireccionalidad de la comunicación en las exposiciones presupone la existencia de un público capaz de descodificar los mensajes y de aceptar las convenciones implícitas en el producto comunicativo. Exposiciones con ese enfoque de la comunicación, puede afirmarse, son representativas de un tipo de museo, que de acuerdo Hernández (2015), puede ser “[...] considerado como una realidad obsoleta donde solo prima la pasividad y el elitismo, la transmisión ideológica unidireccional y 
su imposición obligatoria” (p. 152).

Más allá de exposiciones pensadas y creadas a la sombra del modelo comunicativo de transmisión de la información, la unidireccionalidad del mensaje podría subvertirse creando exposiciones en función de las posibilidades, necesidades e intereses del público en cuestión. Desde este punto de vista, siguiendo a Cury (2007), se podría llegar a pensar en los visitantes como participantes del proceso curatorial, toda vez que al igual que el personal del museo involucrado, contribuyen a la resignificación de los objetos ${ }^{3}$. En este caso, las exposiciones podrían funcionar como "[...] procesos de aprehensión de la realidad y catalizadores de voluntades, aspiraciones y deseos de intervención" (Mountinho, 2008, p. 39, traducción nuestra).

Si bien puede afirmarse la existencia de un proceso de reorientación en dirección a colocar un mayor énfasis en el proceso de recepción del mensaje, dirigido a un mayor protagonismo de los visitantes y a mayores posibilidades para un aprendizaje contextualizado; por otro lado, este hecho visto como tendencia está lejos de ocultar la preponderante presencia de exposiciones que todavía responden a la transmisión unidireccional del mensaje. Esta opinión encuentra respaldo en Cury (2011), cuando señala que aunque los museos perciben a sus públicos como su principal referencia, en la práctica, en estas instituciones persisten modelos hegemónicos que responden a intereses de mercadotecnia y funcionalistas o de naturaleza conductista.

Ante la permanencia y resistencia al cambio de modelos pasivos de la comunicación en museos, Marandino et al. (2008) valora la idea de convivencia entre abordajes pasivos y participativos, lo que "[...] se refiere a la necesidad de disponer, para el público, informaciones y contenidos, y también espacios de encuentro y diálogo, de forma que diferentes posturas y visiones de mundo tengan voz y puedan ser legitimadas" (p. 17, traducción nuestra). En esta pluralidad, a la que subyacen disímiles modelos de comunicación, aclara la autora, compete al educador tener claridad sobre los modelos que subyacen a sus acciones y decidir a partir de cuales desarrollar sus acciones educativas.

\section{El ambiente y sus problemas socioambientales en las exposiciones de museos}

En este singular y variopinto ámbito educativo del museo, desde mediados del siglo XX, como resultado de acontecimientos experimentados en el mundo ${ }^{4}$, comienzan a entrar y a ser socializadas, ideas, enfoques y experiencias que apuntan a una preocupación del museo con su realidad política y social. Este movimiento del museo es resultado de la enunciación de nuevas exigencias de la sociedad sobre estas instituciones, en dirección a su democratización, a la inclusión

3 Este enfoque se corresponde con el modelo cultural de la comunicación, que según Hooper-Greenhill (2010), entiende a la comunicación como interacción, como un conjunto de procesos de crear sentidos como parte de la cultura compleja y desigual de la vida cotidiana.

4 Demanda social de posguerra (Cury b, 2005); revueltas estudiantiles de mayo de 1968 (Hernández, 2007); y surgimiento y desarrollo de movimientos sociales (Leite, 2014). 
de problemas contemporáneos en su discurso, y a un mayor dinamismo y participación de los públicos en las funciones de los museos.

Como parte de ese proceso de apertura a la sociedad en las décadas del $60 \mathrm{y}$ del 70, con el advenimiento de la crisis ambiental ${ }^{5}$, algunos museos se hacen eco de los problemas socioambientales y comienzan, al menos tímidamente, a presentarlos en sus acciones educativas. Consecuentemente, son reconocidos como instituciones con potencialidades para la formación de la ciudadanía en materia ambiental. Así, por ejemplo, en fecha tan temprana como el año 1971, el presidente del New York Botanical Garden, Willian Campbell reconoce que:

Los museos están admirablemente equipados, mediante sus diversas colecciones, su experiencia en exponer, su larga experiencia en conservación, y su vasta clientela, para jugar un importante papel, en sensibilizar al público, sobre los problemas ambientales, así como de los medios para su solución. (Steere, 1971 citado en Stine, 2002, p. 576, traducción nuestra).

En el ámbito de décadas posteriores del mismo siglo, Mountinho (1994) afirma que los museos, más allá de sus funciones tradicionales, pretenden funcionar como medios de comunicación de las preocupaciones contemporáneas. Un poco más tarde, para los comienzos del siglo XXI, Hernández (2007) opina que museos no ajenos a una sensibilidad ecológica ${ }^{6}$, que caracteriza la sociedad de los comienzos de este siglo, presentan en sus exposiciones "[...] problemas relativos a la degradación del medio ambiente, a la habitabilidad del planeta y a la reconstrucción de ecosistemas, a la desaparición de las especies, a la capa de ozono o al problema de los desechos y a la urgencia de su reciclaje" (p. 12).

La presentación de los problemas socioambientales en las exposiciones de museos en base a la literatura científica encontrada (Auricchio, 2001; Fortin-Debart 2003; González et al., 2002; Guimarães \& Vasconcellos 2006; Marandino \& Diaz Rocha 2011; Meyer, \& Meyer 2014; Redondo et al., 2008; Segarra et al., 2008; Van-Praët 1996; Vilches et al., 2006), parece ser un asunto concerniente a museos que de alguna forma lidian con la relación sociedad-medio ambiente desde el lente de las ciencias de la naturaleza. Este ámbito de las ciencias, siguiendo a Foladori (2001) y a Layrarguez (2002), representado en la biología y la ecología científica, fue el primero que se interesó por la cuestión ambiental. Ese interés pudo ser la expresión de un prejuicio presente todavía en múltiples ámbitos de la sociedad, que entiende y en consecuencia reduce el medio ambiente y sus problemas a su dimensión biofísica.

Ese tipo de tratamiento dado a los problemas socioambientales, una vez presente en las exposiciones, propicia la socialización de mensajes más alineados con

\footnotetext{
5 Se entiende aquí a la crisis ambiental, siguiendo a Leff (2002) como "[...] síntoma de una crisis de civilización, marcado por el modelo de modernidad regido bajo el predominio de la razón tecnológica por encima de la organización de la naturaleza" ( p. 17).

6 Adopta como consenso la existencia de una crisis ambiental de origen antropocéntrico, aunque es multidiversa en relación al sujeto-interprete y sus diversas lecturas sobre las relaciones individuo-sociedad-medio ambiente, las causas y soluciones de la crisis ambiental, entre otras cuestiones.
} 
la reproducción y mantenimiento del estatus de crisis social y ambiental vigente, que con su subversión y superación. En ese sentido Foladori (2001) opina que al atenderse las causas inmediatas que obedecen a razones técnicas circunscritas a las ciencias de la naturaleza, se ignoran las causas últimas vinculadas a las desiguales relaciones sociales, atendidas por las ciencias sociales y humanas. Este despropósito es la expresión de un estado del conocimiento insensible y políticamente desfavorable a la comprensión de la naturaleza compleja de la crisis ambiental.

De acuerdo con Leff (2000), la crisis ambiental vino a cuestionar el conocimiento científico y sus modos de producción en la modernidad, pues la ciencia de matriz positivista, "[...] ha generado un desconocimiento del mundo, un conocimiento que no sabe de sí mismo [...]” (Leff, 2000, p. 7). Frente a esta compleja situación, al menos en el plano epistemológico, siguiendo a este mismo autor, se necesita una reorientación de las ciencias en función de construir un pensamiento holístico, que sea capaz de reintegrar la realidad fragmentada a la luz de paradigmas inter y transdisciplinarios.

En estudios realizados por González, Gil y Vilches (2002), en museos de ciencias; y por Redondo, Gil y Vilches (2008), en museos etnológicos y antropológicos, se apunta a una presentación incidental, dispersa y muy superficial de los problemas planetarios. Por otra parte, Borroto (2019) en una de las dos exposiciones analizadas durante su estudio, observó que problemas ambientales relacionados con la pérdida o disminución de la biodiversidad eran presentados como tema principal en muestras expositivas, en algunos puntos de la exposición. No obstante, dicha presentación siempre era realizada en los límites de disciplinas como la biología o la ecología científica, limitando el medio ambiente y sus problemas a su dimensión biofísica, y desconectados del contexto local.

A partir de estas informaciones, tal vez no sería descabellado pensar en la presentación de los problemas socioambientales en museos como de unidimensional, incidental, dispersa y muy superficial, lo que no negaría la emergencia de instituciones, principalmente en los últimos años, que den más representatividad a este asunto en sus exposiciones. No obstante, este tema reclama el desarrollo de nuevos estudios de naturaleza cuantitativa y cualitativa que puedan dar cuenta de un amplio rango de museos, así como sumergirse con profundidad en los espacios expositivos de esas instituciones.

Más allá de la presentación de los problemas socioambientales, las exposiciones de museos como mediadoras de la relación entre el ser humano y su cultura material, han socializado desde mucho antes representaciones de la naturaleza y el medio ambiente. Esta aseveración no debería parecer rara si se piensa en sintonía con Van Präet (2004) que:

La naturaleza y el medio ambiente tejen relaciones con los museos que son sujetos a representaciones científicas y sociales que nuestras sociedades han tenido en el pasado, y continúan teniendo hoy, no solo de la naturaleza, sino además del patrimonio, y por supuestos, de los museos. (Van-Praët, p. 114, 2004, traducción nuestra). 
Esas entidades, entendidas como representaciones, se asumen como construcciones culturales de carácter histórico que a lo largo del tiempo y a través de diferentes racionalidades, culturas y sociedades, han sido percibidas con identidades diversas,- sujetas a y como agentes de-, diversas formas del ser humano entender, sentir y relacionarse con su entono. En esta diversidad, de acuerdo con Diegues (2001) algunas representaciones se imponen sobre otras, como expresión de intereses en juego y de relaciones de poder.

En ese sentido, como parte del mensaje expositivo, la presentación de representaciones del medio ambiente o de la naturaleza pueden estar sugiriendo formas prescritas de los seres humanos percibir y relacionarse con su entorno, en sintonía con la perpetuación del estado de crisis ambiental. O por el contrario, -menos probable pero no imposible-, favorables al enfrentamiento de la crisis, al sugerir formas alternativas de existencia basadas en una convivencia respetuosa del ser humano en sociedad y con su entorno.

A partir del juego de las representaciones sobre el medio ambiente y la naturaleza en el museo, pudiera pensarse de acuerdo Kaplan (1995) y Macdonald (1998), al espacio expositivo, - distante de cualquier idea de ingenuidad —, como una arena política donde voces y saberes, en el marco de relaciones de poder, compiten por la hegemonía del discurso expositivo. Este discurso podría considerarse influyente en los públicos del museo, si se considera de acuerdo con Stine (2002), que estas instituciones son percibidas por los ciudadanos como confiables, en relación al conocimiento que socializan.

A la luz de las anteriores consideraciones, no se trataría de que museos adopten una postura neutral en la representación de la naturaleza o del medio ambiente en sus exposiciones, - algo de por sí imposible —, sino que se asuman como instituciones en disputa por los sentidos y significados de lo ambiental ${ }^{7}$. Además, conscientes de ese papel, apuesten por representaciones que legitimen al medio ambiente o a la naturaleza como un bien común, pero diferenciado ${ }^{8}$, actuando en consecuencia como un instrumento de resistencia cultural y acción política.

En el ámbito de las representaciones sobre el medio ambiente en las exposiciones de museos de historia natural, Fortin-Debart (2003) proporciona algunas herramientas que pueden ayudar a esclarecer, mediante el estudio de la museografía de las exposiciones, algunos tipos de representaciones sobre el medio ambiente sugeridas a los visitantes. En tal sentido, la autora propone una representación biocéntrica, deducible de la presentación de especímenes en el marco de lógicas taxonómicas; una representación ecocéntrica, típica de dioramas, donde es posible apreciar relaciones entre los especímenes expuestos y de estos con factores abióticos de sus entornos; una representación antropocéntrica, que evoca problemas que afectan al ser humano; y por último una representación

\footnotetext{
7 De acuerdo con Kesselring (2000), “[... ] la consciencia de que nuestras concepciones actuales de la Naturaleza no son las únicas ni son evidentes, y el descubrimiento de otras posibles concepciones tal vez puedan inspirar la búsqueda de alternativas" (p. 154, traducción nuestra).

8 Los individuos y los grupos humanos perciben y se relacionan con el medio ambiente de forma diferenciada, teniendo diferentes cuotas de responsabilidades y beneficios frente a la situación de crisis ambiental.
} 
sociocéntrica, que sugiere al medio ambiente como un campo de relaciones sociales.

En su estudio de museos de historia natural franceses, la autora señala la ausencia de la representación sociocéntrica del medio ambiente. Similares resultados han sido señalados por Marandino y Diaz Rocha (2011) en el análisis de las exposiciones del Biodôme/Canadá y de la Fundación Zoobotánica/FZB/Brasil; y por Borroto y ToralesCampos (2019) para tres museos de historia natural del sur de Brasil. Estos resultados indican, al menos para museos de historia natural, a la luz de la tipología propuesta por Fortin-Debart (2003), la ausencia de la dimensión social en el tratamiento del medio ambiente y sus problemas en las exposiciones.

A partir de estas reflexiones, el medio ambiente y sus problemas socioambientales parecen constituirse en un gran reto para los museos, cuando se trata de su presentación en las exposiciones, principalmente si se considera a instituciones que se asocian a disciplinas científicas excluyentes de otras áreas del conocimiento. En estos casos, más allá de que el conocimiento científico sea influido y también modificado en función de las visiones de los actores ${ }^{9}$ y conocimientos procedimentales ${ }^{10}$, el conocimiento disciplinar que emana de la investigación del acervo del museo, se constituye en conocimiento de referencia en la elaboración del mensaje de la exposición. Como consecuencia el mensaje socializado ignora la naturaleza multifacetada de las cuestiones socioambientales, pudiendo influir en visiones fragmentadas y reduccionistas sobre el medio ambiente en los públicos del museo. Por otra parte, para instituciones como los museos que históricamente han socializado la cultura material mediante la presentación de objetos, los problemas socioambientales que surgen de ideas abstractas y complejas se convierten en un reto a la imaginación y a la creatividad de los curadores en la realización de las exposiciones.

Estos problemas presentes en la socialización de temas socioambientales son reforzados en las exposiciones cuando son presentados en el marco de modelos pasivos de la comunicación. En estos casos, obedeciendo a una trasmisión del mensaje unidireccional, el conocimiento socializado se presenta descontextualizado de las realidades socioambientales de los públicos de los museos. En este sentido, Morin (2003) aporta una importante pauta sobre la responsabilidad de un discurso de estas características cuando opina que "Una inteligencia incapaz de percibir el contexto y el complejo planetario permanece ciega, inconsciente e irresponsable" (p. 15 traducción nuestra).

Para sortear estos inconvenientes en la presentación del medio ambiente y sus problemas socioambientales, los museos necesitarán de cambios en su cultura, estructura y personal, en dirección a la construcción y socialización de un conocimiento resultado del diálogo de saberes ${ }^{11}$, que sea capaz de pervertir la sumisión del discurso expositivo a la ciencia disciplinar. Además, necesitarán de una reorientación de la atención del museo

9 Curadores, diseñadores, educadores, etc.

10 Conocimientos museológicos, museográficos, didácticos, etc.

11 Saberes de sentido común, saberes sabios, saberes museológicos, saberes de la comunicación, saberes de la educación, entre otros saberes. (Marandino, 2005). 
hacia sus públicos, mediante la adopción de modelos de comunicación participativos, en el marco de los cuales los públicos del museo sean percibidos como habitantes de un territorio.

\section{Conclusiones}

Con base en las cuestiones discutidas, se concibe a la exposición como una acción comunicativa y educativa que se constituye en base a determinadas estrategias comunicativas y conocimientos elegidos, que son la expresión de determinadas visiones de ciencia, de sociedad, de comunicación, de educación y de cultura, presentes en los actores del proceso curatorial, que permanecen sensibles a las políticas institucionales del museo y de más allá de sus muros. En este ámbito de influencias sobre la identidad del discurso expositivo son representados ciertos intereses dominantes o emergentes y subversivos, que definen la posición del museo antes su sociedad.

Los museos públicos, a partir del universo bibliográfico consultado, parecen estar manifestando una cierta morosidad, tal vez resistencia, acunada en lógicas disciplinares, que a la larga pueden estar respondiendo a intereses del capital insensibles a la situación de crisis ambiental. Esos intereses subyacen solapadamente al discurso expositivo y emplazan a estos museos como instituciones mantenedoras y/o reproductoras del status vigente de crisis ambiental. Esta situación se infiere de la desatención a la problemática ambiental o a través del tratamiento unidimensional dado a los problemas socioambientales en las exposiciones; así como en la preponderancia de representaciones del medio ambiente que ignoran su componente social.

La crisis ambiental, al igual que otros problemas contemporáneos que hoy afectan a la humanidad, coloca en cuestión a las instituciones sociales en su rol de responder a las demandas de sus sociedades. Más específicamente, los problemas socioambientales, embisten las anquilosadas estructuras disciplinares de muchos museos que se dedican a la socialización de la ciencia, y que se mantienen funcionando con lógicas surgidas siglos atrás. Lógicas que actualmente son contestadas por la complejidad de los problemas actuales y por las emergencias de nuevas demandas sociales. Esa situación exige de un esfuerzo constante en dirección a la renovación de estas instituciones como garantía de su existencia. En este caso, por la crítica a su lógica discursiva amparada en viejas recetas disciplinares desconectadas de los intereses, necesidades y posibilidades de sus públicos.

Delante de ese escenario, y tomando en cuenta la poca y discontinua producción científica, queda claro la necesidad de investigaciones en esta área del conocimiento, que aporten elementos que permitan reforzar el vector social y ambiental de la institución museo. En esta lógica de pensamiento se enmarca el presente artículo, que procuró poner en cuestión el papel de museos públicos frente a la situación de crisis ambiental, mediante la discusión de la presentación de esta temática en sus exposiciones. 


\section{Referencias}

Auricchio, A. L. R. (2001). Os museus e a questão ambiental. Revista Educação: Teoria e Prática, 9(16), 49-100. https://terrabrasilisdidaticos.com.br/wp-content/ uploads/2014/07/museu_e_a_questao_ambiental.pdf

Borroto, I. R. (2019). La educación ambiental en el museo de historia natural: un análisis de las acciones en dos museos del sur de Brasil. (Tese de doutorado). Programa de PósGraduação em Educação, Setor de Educação, Universidade Federal do Paraná. https:// acervodigital.ufpr.br/handle/1884/64002

Borroto, I. R., \& Torales-Campos, M. A. (2019). La educación ambiental en museos de historia natural del sur de Brasil. REMEA-Revista Eletrônica do Mestrado em Educação Ambiental, 36(1), 63-78. https://doi.org/10.14295/remea.v36i1.8937

Chagas, M. S. (2011). Museus, memórias e movimentos sociais. Cadernos de Sociomuseologia, (41), 5-16. https://revistas.ulusofona.pt/index.php/ cadernosociomuseologia/article/view/2654

Cury, M. X. (2005a). Comunicação museológica: uma perspectiva teórica e metodológica de recepção. (Tese de Doutorado em Ciências da Comunicação). Escola de Comunicações e Artes da Universidade de São Paulo. https://www.researchgate.net/ publication/259866616_Comunicacao_Museologica_-_Uma_Perspectiva_Teorica_e_ Metodologica_de_Recepcao

Cury, M. X. (2005b). Comunicação e pesquisa de recepção: uma perspectiva teóricometodológica para os museus. História, Ciências, Saúde-Manguinhos, (12), 365-380. https://doi.org/10.1590/S0104-59702005000400019

Cury, M. X. (2007). Comunicação museológica em museu universitário: pesquisa e aplicação no Museu de Arqueologia e Etnologia-USP. Revista CPC, (3), 69-90. https:// doi.org/10.11606/issn.1980-4466.v0i3p69-90

Cury, M. X. (2011). Museu em Transição. In Sistema Estadual de Museus SISEM SP,. (Orgs.), Museus: O que são, para que servem? (pp. 17-28). Brodowski.

Cury, M. X. (2013). Educação em museus: panorama, dilemas e algumas ponderações. Ensino em Re-Vista, 20(1), 13-2. http://www.seer.ufu.br/index.php/emrevista/article/ view/23206

Diegues A. C. S. O. (2001). O Mito Moderno da Natureza Intocada. Hucitec.

Falk, J. H., \& Dierking, L. D. (2000). Learning from museums: Visitor experiences and the making of meaning. AltaMira Press.

Falk, J. H. (2005). Free-choice environmental learning: framing the discussion. Environmental Education Research. 11(3), 265-280. https:/doi. org/10.1080/13504620500081129 
Falk, J. H., Dierking, L. D., \& Adams, M. (2006). Living in a learning society: Museums and free-choice learning. In S. Macdonald,. (Orgs.), A companion to museum studies (pp. 323-339). Blackwell Publishing Ltd.

Falk, J. H., Heimlich, J. E., \& Foutz, S. (2009). Free-choice learning and the environment. Altamira Press.

Foladori, G. (2001). Limites do desenvolvimento sustentável. Unicamp.

Fortin-Debart, C. (2003). Le Musee de Sciences Naturelles, un partenaire de l'école pour une education relative a l'environnement: du message scientifique au débat de société. Vertigo-la revue électronique en sciences de l'environnement, 4(2), 1-14. https://doi. org/10.4000/vertigo.4494

Gonzáles, M. M. H., Gil, P. D., \& Vilches, P. A. (2002). Los museos de ciencias como instrumentos de reflexión sobre los problemas del planeta. TED: Tecne, Episteme y Didaxis, 12, 98-112. https:// doi.org/10.17227/ted.num12-5968

Guimarães, M., \& Vasconcellos, M. (2006). Relações entre educação ambiental e educação em ciências na complementaridade dos espaços formais e não formais de educação. Educar, 27, 147-162. https://doi.org/10.1590/S0104-40602006000100010

Hein, G. E. (2002). Learning in the Museum. Routledge.

Hein, G. E. (2005). The role of museums in society: Education and social action. Curator, 48(4), 357-363. https://doi.org/10.1111/j.2151-6952.2005.tb00180.x

Hein, G. E. (2006). Museum Education. In S. Macdonald,. (Orgs), Companion to Museum Studies (pp. 340-352). Blackwell Publishing Ltd.

Hernández, F. H. (2007). La museología ante los retos del siglo XXI. e-rph-Revista electrónica de Patrimonio Histórico, (1), 333-358. https://revistaseug.ugr.es/index.php/erph/article/view/3326

Hernández, F. H. (2015). Conferência proferida na Aula Inaugural do Programa de PósGraduação em Museologia e Patrimônio-UNIRIO/MAST, em 16 de março de 2015, Rio de Janeiro-RJ. Museologia e Patrimônio - Revista Eletrônica do Programa de Pós-Graduação em Museologia e Patrimônio - Unirio | MAST, 8(2), 143-167. http://revistamuseologiaepatrimonio.mast.br/ index.php/ppgpmus/issue/view/22/showToc

Hooper-Greenhill, E. (1988). The Art of Memory and Learning in the Museum. The Challenge of GCSE. The International Journal of Museum Management and Curatorship, 7(2), 129-137. https://doi.org/10.1016/0260-4779(88)90017-9

Hooper-Greenhill, E. (2000). Changing Values in the Art Museum: rethinking communication and learning. International Journal of Heritage Studies, 6(1), 9-31. https://doi. org/10.1080/135272500363715

Hooper-Greenhill, E. (2003). Museums and the Shaping of Knowledge. Routledge.

Hooper-Greenhill, E. (2004). Museum and their Visitors. Routledge.

Hooper-Greenhill, E. (2007). Museum and education. Routledge. 
Hooper-Greenhill, E. (2010). Changing values in the art museum: Rethinking communication and learning. International Journal of Heritage Studies, 6(1), 9-31. https://doi. org/10.1080/135272500363715

Kaplan, F. E. (1995). Exhibitions as communicative media. In E. Hooper-Grennhill,. (Orgs.), Museum, media, message (pp. 37-58). Routledge.

Kesselring, T. (2000). O conceito de natureza na história do pensamento ocidental. Episteme, (11), 153-172. http://www.thomaskesselring.com/uploads/4/6/1/4/46146447/conceito_de_ natureza_1.pdf

La Belle, T., J. (1976). Nonformal education and social change in Latin America. UCLA Latin American Center Publications Uniyersity of California.

Layrargues, P. P. (2002). A crise ambiental e suas implicações na educação. In J. S. Quintas,. (Org.), Pensando e praticando a educação ambiental na gestão do meio ambiente (pp. 159-196). IBAMA.

Leff, E. (2000). Pensar la complejidad ambiental. In E. Leff,. (Org.), La complejidad ambiental (pp. 7-53). Siglo XXI.

Leff, E. (2002). Saber Ambiental. Sustentabilidad, racionalidad, complejidad, poder. Siglo XXI.

Leite, P. P. (2014). A nova museologia e os movimentos sociais em Portugal. Revista Cadernos do Ceom, 27(41), 193-223. https://bell.unochapeco.edu.br/revistas/index. $\mathrm{php} / \mathrm{rcc} /$ issue/view/168/showToc

Lindauer, M. A. (2007). Critical museum pedagogy and exhibition development: A conceptual first step. In S., J. Knell, S. MacLeod \& S. Watson (Orgs), Museum Revolutions: How Museums Change and are Changed (pp. 303-314). Routledge.

Macdonald, S. (1998). Exhibitions of power and powers of exhibition: an introduction to the politics of display. In S. Macdonald., (Orgs), The politics of display: Museums, science, culture (pp. 1-14). Routledge.

Macdonald, S., \& Silverstone, R. (1990). Rewriting the museums fictions: taxonomies, stories and readers. Cultural Studies, 4(2), 176-191. https://doi. org/10.1080/09502389000490141

Marandino, M. (2002). A biologia nos museus de ciências: a questão dos textos em bioexposições. Ciência \& Educação (Bauru), 8(2), 187-202. https://doi.org/10.1590/ S1516-73132002000200004

Marandino, M. (2005). Museus de Ciências como Espaços de Educação In D. G. Vidal \& B., G. Figueiredo,. (Orgs.), Museus: dos Gabinetes de Curiosidades à Museologia Moderna (pp. 165-176). Argumentum.

Marandino M., Bizerra, A. F., Navas, A. M., Fares, D. C., Monaco, L. M., Martins, L.C., Garcia, V. A. R., \& Souza, M. P. C. de. (2008). Educação em museus: a mediação em foco. Geenf/FEUSP 
Marandino, M., \& Díaz Rocha, P. E. (2011). La Biodiversidad en exposiciones inmersivas de museos de ciencias: implicaciones para educación en museos. Enseñanza de las Ciencias, 29(2), 221-236. https://www.raco.cat/index.php/Ensenanza/article/ download/243834/353437

Maxwell, L. E., \& Evans G.W. (2002). Museums as learning settings: The importance of the physical environment. Journal of Museum Education, 27(1), 3-7. https://doi.org/10. $1080 / 10598650.2002 .11510454$

Meyer G., C., \& Meyer G., C. (2014). Educação Ambiental em Museus de Ciência: diálogos, práticas e concepções. Revista Brasileira de Educação Ambiental (RevBEA), 9(1), 70-86. https://doi.org/10.34024/revbea.2014.v9.1822

Morin, E. (2003). A cabeça bem-feita: repensar a reforma, reformar o pensamento. Bertrand.

Mountinho, C. M. (1994). A construção do objeto museológico. Edições Universitárias Lusófonas.

Mountinho, C. M. (2008). Os museus como instituições prestadoras de serviços. Revista de Humanidades e Tecnologias, (12), 36-43. https://revistas.ulusofona.pt/index.php/ rhumanidades/article/view/987

Mountinho, C. M. (2014). Definição evolutiva de sociomuseologia: proposta de reflexão. Revista Cadernos do Ceom, 27(41), 423-427. https://bell.unochapeco.edu.br/revistas/ index.php/rcc/article/view/2617

Redondo, L., Gil, D., \& Vilches, A. (2008). Los museos etnológicos como instrumentos de formación ciudadana para la sostenibilidad. Didáctica de las ciencias experimentales $y$ sociales, (22), 67-84.

Segarra, A., Vilches, A., \& Gil, D. (2008). Los museos de ciencias como instrumentos de alfabetización científica. Didáctica de las ciencias experimentales y sociales, (22), 85-102. https://dialnet.unirioja.es/descarga/articulo/2934596.pdf.

Silverstone, R. (2002). The medium is the museum: on objects and logics in times and spaces. In R. Miles, \& L. Zavala. (Orgs), Towards the Museum of the Future (pp. 161176). Routledge.

Stine, J. K. (2002). Placing environmental history on display. Environmental History, 7(4), 566-588. https://www.jstor.org/stable/3986057?seq=1

Van-Praët, M. (1996). Cultures scientifiques et musées d'histoire naturelle en France. Hermès, (2), 143-149. https://www.cairn.info/revue-hermes-la-revue-1996-2-page-143. htm? contenu=resume

Van-Praët, M. (2004) Heritage and scientific culture: the intangible in science museums in France. Museum International, 56(1-2),113-121. https://doi.org/10.1111/j.13500775.2004.00465.x 
Vilches, A., Gil, P. D., Gonzáles, M., \& Gonzalés, E. (2006). La atención a la situación de emergencia planetaria en los museos de ciencias: el inicio de un cambio necesario. Ciência \& Educação (Bauru), 12(1), 39-55. https://doi.org/10.1590/S1516-73132006000100005

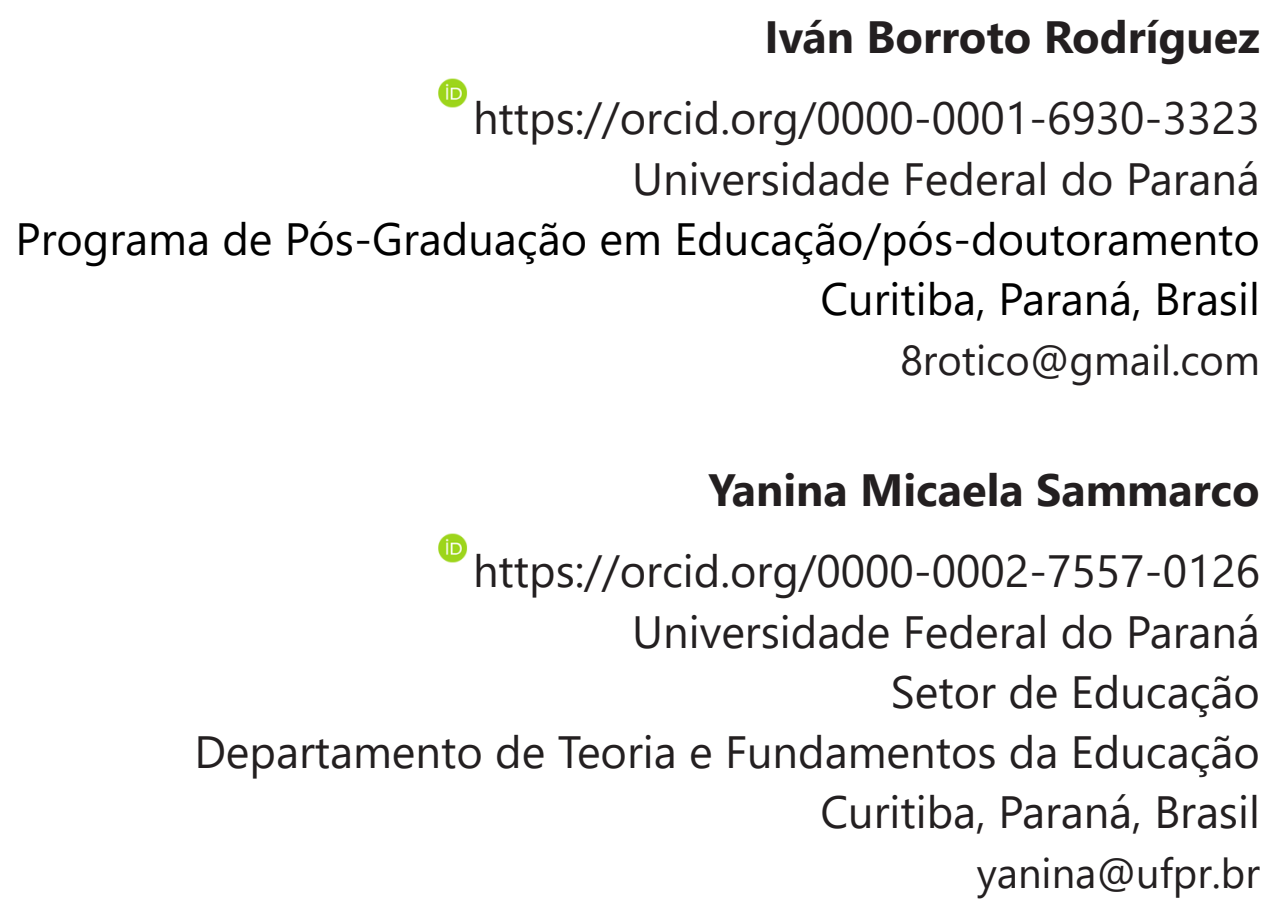

Recibido el 19 de febrero de 2020

Aceptado el 17 de julio de 2020

Publicado el 10 de agosto de 2020 